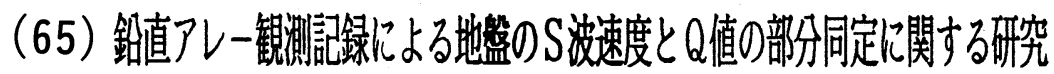

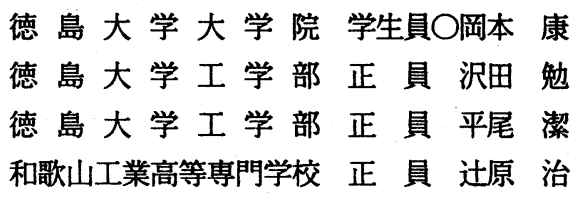

\title{
1.まえがき
}

近年、地震波を地表及び地中で同時観測する鉛直アレ一観測が行われるようになり、これらの記録を用い て、地震時における地盤の動特性を同定しようとする研究が行われている。これまで筆者らも、観測記録か ら得られる伝達関数とモデルの自乗和誤差を最小にするという評価基準を用いて、地盤のS 波速度とQ値を 推定した"”。この手法では、地中最も梁く設置された地震計より地表までの地盤各層のパラメータを一度に 推定する。そのため、地盤モデルの層数が増えればそれだけ演算時間も增え、さらに解の精度も低下すると 考えられ、従来の手法では同定不能な場合も生じてくる。しかし、地震時の地盤では、ある特定の層の動特 性のみ重要となる場合がある。本報告では、地中の 3 点で同時観測記録が得られているとし、これらの記録 が得られた最上点と最下点の間の各層の $\mathrm{S}$ 波速度と $\mathrm{Q}$ 值を部分的に同定する、いわゆる部分同定法を提案し その妥当性を検討した。また、観測記録に含まれるノイズの影響を低減するため、スペクトルの平滑化を考 虑した同定手法"2を解析に取り入れ解の推定精度を検討した。

2. 地盤同定問題の定式化

一般に、比較的深い震源の近距離地震による地盤震動の強震部では S 波速 度が卓越し、その震央直角成分は、SH波であると考えられる。図一1に示 す水平成層構造をもつモテル地盤において鉛直下方より $\mathrm{S} \mathrm{H}$ 波が入射すると 仮定し、地中 3 点で得られた鉛直アレ一観測記録より、記録が得られた最上 点と最下点の間の各層の $\mathrm{S}$ 波速度と $\mathrm{Q}$ 值を部分的に同定する問題を考える。 層厚及び密度は、標準貫入試験等により比較的精度よく推定されるため既知 とし、Q值は周波数によらず一定であると仮定している。

いま、図ー 1 において第 $\mathrm{p}$ 層上面、第 $\mathrm{q}$ 層下面、及び第 $\mathrm{r}$ 層下面において 同時観測記録が得られているとし、以下では便宜上これらの点をそれぞれ $p$ 点、 $q$ 点、及び $r$ 点とする。これら各点での変位振幅を $u_{p}, u_{q}, u_{r}$ とし、せ ん断応力を $\tau_{p}, \tau_{q}, \tau_{\mathbf{r}}$ とすると、重複反射理論より次の 2 式が得られる ${ }^{3)}$ 。

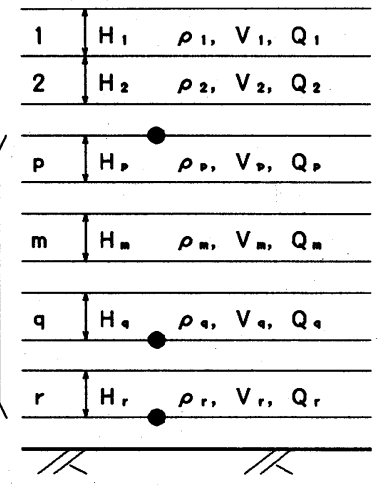

困- 1 水平成層地盤

$$
\left\{\begin{array}{l}
u_{q} \\
\tau_{q}
\end{array}\right\}=\left[R_{q}\right]\left\{\begin{array}{l}
u_{p} \\
\tau_{p}
\end{array}\right\},\left\{\begin{array}{l}
u_{r} \\
\tau_{r}
\end{array}\right\}=\left[R_{r}\right]\left\{\begin{array}{l}
u_{p} \\
\tau_{p}
\end{array}\right\}
$$

ここで、

$$
\left[R_{q}\right]=\left[S_{q}\right]\left[S_{q-1}\right]\left[S_{q-2}\right] \cdots\left[S_{m}\right] \cdots\left[S_{p+1}\right]\left[S_{p}\right], \quad\left[R_{r}\right]=\left[S_{r}\right]\left[S_{r-1}\right]\left[S_{r-2}\right] \cdots\left[S_{m}\right] \cdots\left[S_{p+1}\right]\left[S_{p}\right]
$$

上式に含まれる $2 \times 2$ 行列 $\left[\mathrm{S}_{\mathrm{m}}\right](\mathrm{m}=\mathrm{p}, \mathrm{p}+1, \cdots, \mathrm{r}-1, \mathrm{r})$ は第 $\mathrm{m}$ 層の状態を表す行列で、その成分は次式で与え られる。

$$
\left\{\begin{array}{l}
S_{m \cdot 11}=\left[\exp \left(i a_{m} \omega\right)+\exp \left(-i a_{m} \omega\right)\right] / 2 \\
S_{m \cdot 21}=i b_{m} \omega\left[\exp \left(i a_{m} \omega\right)-\exp \left(-i a_{m} \omega\right)\right] / 2 \\
S_{m \cdot 12}=\left[\exp \left(i a_{m} \omega\right)-\exp \left(-i a_{m} \omega\right)\right] /\left(2 i b_{m} \omega\right) \\
S_{m \cdot 22}=S_{m \cdot 11}
\end{array}\right.
$$

ここで、w（=2xf） は円振動数、i は虚数単位であり、係数 $\mathrm{a}_{\mathrm{m}}, \mathrm{b}_{\mathrm{m}}$ は次式のようになる。 
式(1)の2つの式より

$$
a_{m}=H_{m} /\left(V_{m} \sqrt{1+i / Q_{m}}\right), \quad b_{m}=\rho_{m} V_{m} \sqrt{1+i / Q_{m}}
$$

$$
u_{q}=R_{q \cdot 11} u_{p}+R_{q \cdot 12} \tau_{p}, u_{r}=R_{r \cdot 11} u_{p}+R_{r \cdot 12} \tau_{p}
$$

ここで、R.ijは行列 Rのij成分である。式(5) の2つの式より $\tau_{p}$ を消去し、 $u_{p}$ にいて解くと

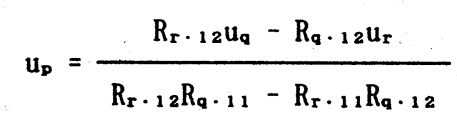

式 (6) の関係より q 点、 $\mathrm{r}$ 点で得られる観測記録の複素フーリエスペクトルを $\mathrm{F}_{\mathrm{q}}(\mathrm{f}), \mathrm{F}_{\mathrm{r}}(\mathrm{f})$ とすると、 $\mathrm{p}$ 点 での複素フーリエスペクトルを以下のように表すことができる。

$$
F_{p}(f)=\frac{R_{r \cdot 12} F_{q}(f)-R_{q \cdot 12} F_{r}(f)}{R_{r \cdot 12} R_{q \cdot 11}-R_{r \cdot 11} R_{q \cdot 12}}
$$

式(4) からわかるように、式(2) の行列 $\left[R_{\mathrm{q}}\right],\left[\mathrm{R}_{\mathrm{r}}\right]$ を構成する $\left[\mathrm{S}_{\mathrm{m}}\right]$ は、部分的に同定を行う地盤各層の層厚 $\mathrm{H}_{\mathrm{m}}$, 密度 $\rho_{\mathrm{m}}, \mathrm{S}$ 波速度 $\mathrm{V}_{\mathrm{m}}$, 及び $\mathrm{Q}$ 值 $\mathrm{Q}_{\mathrm{m}}$ を含むから、式 (7) の $\mathrm{F}_{\mathrm{p}}(\mathrm{f})$ はこれらの地盤パラメー夕の非線形関数 となる。ここで、地盤各層の層厚 $\mathrm{H}_{\mathrm{m}}$, 及び密度 $\rho_{\mathrm{m}}$ を既知とすると、同定すべきバラメータは $\mathrm{S}$ 波速度 $\mathrm{V}_{\mathrm{m}}$ と $\mathrm{Q}$ 值 $\mathrm{Q}_{\mathrm{m}}, \mathrm{m}=\mathrm{p}, \mathrm{p}+1, \cdots, \mathrm{r}+1, \mathrm{r}$ となる。これら同定すべきパラメータを一般的に $a=\left(a_{1}, a_{2}, \cdots, a_{N}\right)$ として、 式 (7) の $F_{p}(f)$ を $F_{p}(f: a)$ で表すと、パラメータ a は $p$ 点の観溂記録より得られるスペクトル振幅 $\left|F_{p}(f)\right|$ と式 (7) のスベクトル振幅の残差平方和を最小にする次のような評価関数として同定される。

$$
\mathrm{Se}=\sum_{\mathrm{i}=1}^{N R}\left\{\left|\mathrm{~F}_{\mathrm{p}}\left(\mathrm{f}_{\mathrm{i}}: a\right)\right|-\left|\mathrm{F}_{\mathrm{p}}\left(\mathrm{f}_{\mathrm{i}}\right)\right|\right\}^{2} \rightarrow \min
$$

ここで、 $f_{\mathrm{i}}$ は対象とする振動数領域を分割したときの $\mathrm{i}$ 番目の振動数点、Nfはそのときの離散振動数点の

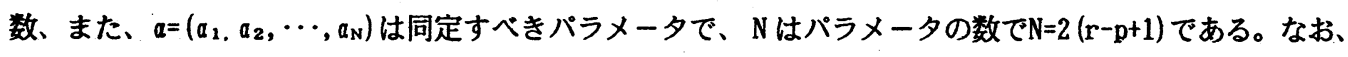
式 (8) の評価関数を最小にする $a$ を決定するために、改良 S L P 法 (改良反復線形計画法) 4)を用いた。 3. 地盤同定問題への平滑化の道入

観测記録には種々の原因でノイズが含まれており、その大小がパラメータの推定精度と染くかかわってい る。したがって、精度の高い同定結果を得るためには、ノイズの影㗽を低隇する必要がある。ノイズの性質 が明らかな場合には、フィルターに通す等により除去することが可能であるが、一般にはわからない。そこ で、周波数領域の解析では、スベクトルの平滑化がなされている。従来の研究では、観測記録より得られた 值のみ平滑化し同定していた。しかし、記録のスベクトルを平滑化するとスペクトルに本来含まれている正 しい情報までゆがめてしまう場合があり、記録のみの平滑化では同定精度を向上させることができない。そ こで本研究では、観測値のみならず理論値をも平滑化することにより、地盤の同定精度を改良する方法を導 入する。

前述の式 (8) の評価関数において、理論値と観測值の両方のスペクトルに平滑化を考虑すると、式(8) の 評価関数は次式のように表される。

$$
\operatorname{Se}=\sum_{i=1}^{N f}\left\{\left|\hat{F}_{p}\left(f_{i}: a\right)\right|-\left|\hat{F}_{p}\left(f_{i}\right)\right|\right\}^{2} \rightarrow \min
$$

ここで、一は平滑化を意味し、| $\hat{F}_{p}\left(f_{i}: a\right)|,| \hat{F}_{p}\left(f_{i}\right) \mid$ は次式のように表される。

$$
\left|\hat{F}_{p}\left(f_{i}: a\right)\right|=\sqrt{\sum_{k=-N b}^{N p} W_{k}\left|F_{p}\left(f_{i+k}: a\right)\right|^{2}} \quad, \quad\left|\hat{F}_{p}\left(f_{i}\right)\right|=\sqrt{\sum_{k=-N b}^{N D} W_{k}\left|F_{p}\left(f_{i+k}\right)\right|^{2}}
$$

ここで、略は振動数点 $\mathrm{f}_{\mathrm{i}}$ においてパワースベクトルの平均をとるときの重み係数である。Nbは平滑化バンド 幅によって決まる振動数点の数を表している。

観测記録に含まれるノイズの影響を低減するために、以上のように平滑化を考慮した解析を行う。また、 
平滑化には種々のスペクトルウィンドウが用いられろが、以下の数値計算においては Parzen ウィンドウを 用いる。

\section{3. 数值計算および考察}

\section{(1) 同定手法の妥当性の検討}

式 (8) の評価関数を用いて、特定の層の $\mathrm{S}$ 波速度とQ 値を部分同定することの妥当性について、計算機シミュ レーションにより検討する。解析に用いた地盤モテルの 諸元を表ー 1 に示す。図ー 2 は、この地盤モデルのS 波 速度とQ值の深さ方向の分布を示したものであり、この モテルの第 8 層、第 9 層、及び第 10 層の 3 層を部分同 定する。部分同定法では、観測記録が 3 点必要であるた め、上述の 3 層のみ同定するには、モデルの第 8 層上 面、第 9 層下面、及び第 10 層下面（基盤面）で観測記 録が得られている必要がある。そこで、これらの点を各

表 -1
\begin{tabular}{|c|c|c|c|c|}
\hline 層番号 & 層厚 $(\mathrm{m})$ & 地盤モ广゙度 $\left(\mathrm{t} / \mathrm{m}^{3}\right)$ & $\mathrm{S}$ 波速度 $(\mathrm{m} / \mathrm{s})$ & Q值 \\
\hline 1 & 10 & 1.4 & 100 & 10 \\
\hline 2 & 10 & 1.5 & 200 & 10 \\
\hline 3 & 10 & 1.6 & 300 & 10 \\
\hline 4 & 10 & 1.7 & 250 & 10 \\
\hline 5 & 10 & 1.8 & 300 & 10 \\
\hline 6 & 10 & 1.9 & 350 & 20 \\
\hline 7 & 10 & 2.0 & 400 & 20 \\
\hline 8 & 10 & 2.1 & 250 & 20 \\
\hline 9 & 10 & 2.2 & 300 & 20 \\
\hline 10 & 10 & 2.3 & 550 & 20 \\
\hline
\end{tabular}
観湖点（図-2の○点）とし、第 10 層下面の入力加速 度波に最大加速 度を100galとし た有帯域ホワイ トノイス（帯域 幅0.1 $\mathrm{H}_{\mathrm{z}} \sim 20.0 \mathrm{H}_{\mathrm{z}}$ $\Delta \mathrm{t}=0.02 \mathrm{sec})$ を 用いて、各観測 点での応答加速 度波を表一 1 の

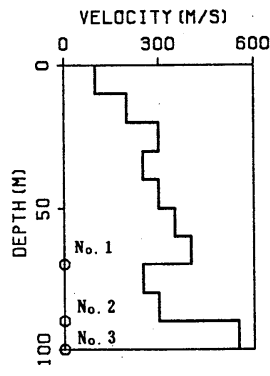

図-2 $\mathrm{S}$ 波速度とQ值の梁さ方向の分布

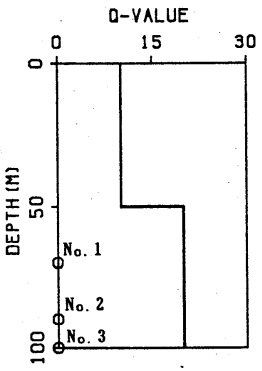

$$
8 \underbrace{}_{\mathrm{N}_{0} .3}
$$
バラメータと重 複反射理論により求めた。図ー3はシミュレートした各

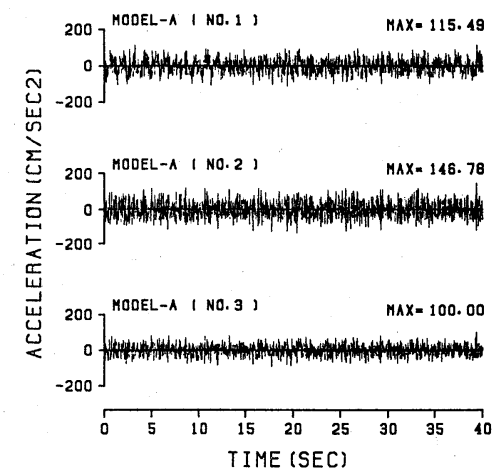

図-3 加速度波形 加速度波であり、これらを用いて解析を行った。同定の 際の初期値は、表一 1 に示す $\mathrm{S}$ 波速度と Q值の 1.5 倍と し、改良S L P 法による繰り返し回数は 100回とした。 また、式 (8) の評価関数は、帯域幅 $0.1 \mathrm{H}_{\mathrm{z}} \sim 20.0 \mathrm{H}_{\mathrm{z}}$ の振動 数領域を 100 等分した振動数点でのスベクトルを対象に した。このような条件により、地盤モデルの第 8層、第 9 層、及び第 10 層を部分同定した結果を図ー4に示 す。図中の細線、中線、及び太線は、それぞれ初期値、 収束值、及び真值に対応している。ただし、この図にお いては、中線 (収束値) と太線 (真值) は完全に一致し ているので両者を識別できない。図より、S波速度とQ 值の各収束值は、ほぼ完全に真值に収束することがわか

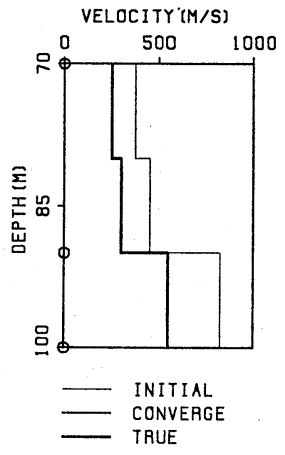

(a) S 波速度

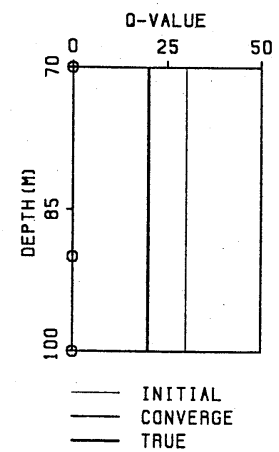

(b) Q值

図-4 同定結果

もので、困の横軸は綠り返し回数、絴軸は S 波速度、あるいはQ值を示している。この図より、各バラメー 夕は約30回程度の結り返し回数で真值に収束することがわかる。以上の結果より、部分同定法で水平成層地 盤内の特定の層の $\mathrm{S}$ 波速度と $\mathrm{Q}$ 值を同定しても妥当な推定値が得られることがわかる。 
（2）平滑化を考慮した同定手法による解の精度

スペクトルの平滑化を考慮した手法を部分同定法に導入 し、钼測記録がノイズを含む場合の推定精度を計算機シミュ レーションにより検討する。解析に用いた地盤モテルは、 先程表ー1で示たものとし、記録が得られた観測点も同じ位 置（図-2の○点）とする。ここでの観測記録は、第 10 層 下面の入力加速度波に最大加速度を100galに基準化したE1 Centro 地震波（SE成分）を用いて先程と同椂に各観測点 での応答加速度波を求めた。そして、これらの各加速度波 に対し、r.m.s.強度で5\%の有帯域ホワイトノイズをそれぞれ 加えたものをノイズ5\%の観測記録とした。図ー6は、シミュ レートした各観測記録 $(\Delta \mathrm{t}=0.02 \mathrm{sec}$, 継続時間 $40.96 \mathrm{sec})$ で あり、これらを解析に用いた。同定の際の初期値、及び改良 S L P 法による繰り返し回数は先程と同様である。また、解 析に用いた評価関数は、平滑化を考慮した式(9) とし、帯域 幅 $0.1 \mathrm{H}_{\mathrm{z}} \sim 20.0 \mathrm{H}_{\mathrm{z}}$ の振動数領域を 100 等分した振動数点でのス ベクトルを対象にした。表ー2は、図ー6のノイズ5\%を含む 観測記録を用いて、平滑化バンド幅を $0.0 \mathrm{H}_{\mathrm{z}}$ から $1.0 \mathrm{H}_{\mathrm{z}}$ まで $0.2 \mathrm{H}_{\mathrm{z}}$ 刻みで変化させて同定した場合の推定誤差を\%で示したものであ る。この表より、平滑化しない場合 (バンド幅 $0.0 \mathrm{H}_{\mathrm{z}}$ ) のQ值の推 定誤差は、50\% 以上と極端に悪いことがわかる。しかし、平滑化を 行った場合、どのバンド幅でもQ值の推定䛊差は改善されている。 特にバンド幅 $0.8 \mathrm{H}_{\mathrm{z}}, 1.0 \mathrm{H}_{\mathrm{z}}$ の場合、Q值の推定誤差は最大で8.6\% の埕差となっている。また、S波速度については、どの場合でも $3 \%$ 以下の譔差内で同定された。このように、観測記録にノイズが含ま れる場合、記録と理論値のスペクトルを同様に平滑化する手法によ

ク、Q值の推定精度が改善されることがわかった。

\section{4. 終わりに}

ある特定の層の $\mathrm{S}$ 波速度と Q值を同定 することを目的とした部分同定法を提案 してその妥当性を検討し、あわせてその 手法にスペクトルの平滑化を導入した場 合の同定精度も検討した。その結果、水 平成層地盤において部分同定が可能であ ること、及び記録と理論值のスペクトル を同様に平滑化する手法は、観測記録に ノイズが含まれる場合に部分同定の推定 精度を改善することがわかった。
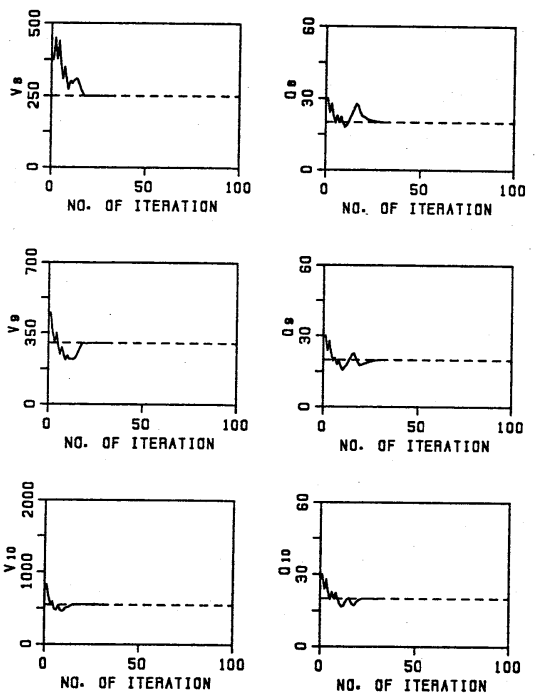

(a) S 波速度

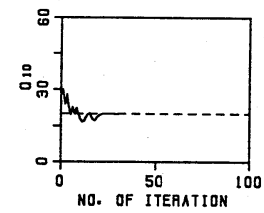

(b) Q值

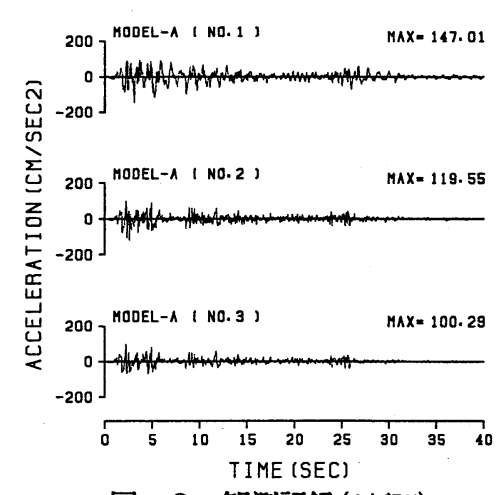

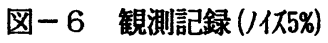

表-2 推定誤差 (/1亿5\%)

\begin{tabular}{|c|c|c|c|c|c|c|}
\hline \multirow{2}{*}{$\begin{array}{c}\text { バンド幅 } \\
\left(\mathrm{H}_{z}\right)\end{array}$} & \multicolumn{3}{|c|}{$\mathrm{S}$ 波速度の誤差(\%) } & \multicolumn{3}{c|}{ Q值の詥差(\%) } \\
\cline { 2 - 8 } & $\mathrm{V}_{8}$ & $\mathrm{~V}_{9}$ & $\mathrm{~V}_{10}$ & $\mathrm{Q}_{8}$ & $\mathrm{Q}_{9}$ & $\mathrm{Q}_{10}$ \\
\hline 0.0 & -2.4 & +1.4 & -0.3 & -55.2 & +132.6 & +216.4 \\
\hline 0.2 & +0.2 & +0.8 & -0.1 & -48.7 & +78.1 & +99.4 \\
\hline 0.4 & +0.5 & +0.4 & -0.3 & -37.6 & +31.5 & +53.2 \\
\hline 0.6 & +0.7 & +0.2 & -0.5 & -24.8 & +8.9 & +25.7 \\
\hline 0.8 & +1.0 & 0.0 & -0.6 & -8.4 & -5.3 & +5.6 \\
\hline 1.0 & +1.1 & -0.1 & -0.6 & -1.4 & -8.6 & +0.7 \\
\hline
\end{tabular}

1)辻原 - 沢田他 : 構造工学論文集, Vol. 36A, pp.747-756,1990,

2)辻原・沢田他：構造工学論文集, Vo1.39A, pp.783-792,1993，3) 土岐：構造物の耐震解析，技報堂, 1981,

4) 沢田・辻原他：土木学会論文集, No. 446/I-19,pp. 205-213,1992 